\title{
Treatment of metastatic refractory colorectal cancer following regorafenib failure
}

\author{
NOBUMICHI TAKEUCHI ${ }^{1}$, KUMIKO KOIKE ${ }^{1}$, SONOMI YOSHIDA ${ }^{1}$, AKIKO KUDO ${ }^{1}$, NODOKA SEKIGUCHI ${ }^{2}$, \\ ATARU NAKAYAMA ${ }^{3}$, KOUJI KUBOTA ${ }^{3}$, TAKASHI ROKUHARA ${ }^{4}$ and MASAYUKI KITAHARA ${ }^{4}$ \\ ${ }^{1}$ Department of Medical Oncology, Ina Central Hospital, Ina, Nagano 396-8555; ${ }^{2}$ Department \\ of Comprehensive Cancer Therapy, School of Medicine, Shinsyu University, Matsumoto, Nagano 396-8621; \\ Departments of ${ }^{3}$ Surgery and ${ }^{4}$ Pharmacology, Ina Central Hospital, Ina, Nagano 396-8555, Japan
}

Received November 8, 2016; Accepted May 25, 2017

DOI: $10.3892 / \operatorname{mco} .2017 .1307$

\begin{abstract}
At present, there is no set strategy for the treatment of patients with colorectal cancer subsequent to the failure of standard treatment, other than the use of regorafenib (RGR) and TAS-102. The best order in which to use these drugs, and their safety and efficacy in combination with other drugs, are currently under investigation. It has been reported that RGR has a resensitizing effect on tumors that have previously failed to respond to anticancer drugs; this makes it a promising salvage therapy for colorectal cancer. The present report describes the results of a retrospective study on 17 patients with metastatic colorectal cancer who received RGR treatment following the failure of standard therapy. Following RGR failure, $71 \%$ of the patients were fit for further anticancer treatment, and these patients survived longer than those who did not receive further treatment. Furthermore, this intervention did not shorten the period of best supportive care. As a considerable number patients were fit for further anticancer therapy after RGR treatment, which resulted in prolonged survival without shortening the period of best supportive care, it may be beneficial for future research to focus on finding the optimal time at which to switch from RGR to further anticancer therapy.
\end{abstract}

\section{Introduction}

Colorectal cancer (CRC) is the third most common cancer worldwide (1). At the time of diagnosis, $>20 \%$ of patients have metastases, and one-third of patients develop metastatic recurrence following the initial surgery (2). The majority of patients with recurrence cannot be cured and are treated with palliative chemotherapy, which has shown great progress in recent years. Two drug combinations, FOLFOX [oxaliplatin with

Correspondence to: Dr Nobumichi Takeuchi, Department of Medical Oncology, Ina Central Hospital, 1313-1 Koshirou Kubo, Ina, Nagano 396-8555, Japan

E-mail: ntakeuti@inahp.jp

Key words: regorafenib, colorectal cancer, salvage chemotherapy 5-fluorouracil (5-FU) and folinic acid] and FOLFIRI (irinotecan with 5-FU and folinic acid), have demonstrated improved outcomes in these patients $(3,4)$. A pooled analysis of phase III studies has shown that exposition to all three active drugs (5-FU, irinotecan, and oxaliplatin) during the course of treatment may be ideal for prolonging the survival of patients (5). The median overall survival times of these patients can exceed 30 months following the adoption of a combination chemotherapy with molecular target therapies in the first-line setting $(6,7)$.

Regorafenib (RGR) is an oral multikinase inhibitor that targets a broad spectrum of angiogenic and stromal kinases. In a well-designed, phase III, international clinical trial, RGR has been shown to prolong overall and progression-free survival times compared with placebos when used as a salvage therapy subsequent to standard treatment comprising 5-FU, irinotecan and oxaliplatin $(8,9)$. In the CORRECT trial, $26 \%$ of the patients underwent another anticancer therapy following RGR treatment; however, the details of this were not reported (8). To date there has been no comprehensive published evidence supporting other treatment following RGR failure in CRC. It has been reported that RGR may have a resensitizing effect on tumors that have previously failed to respond to anticancer treatments (10). In a single-institution study, post-RGR treatment was administered to $32 \%$ of the patients, of which $35 \%$ responded to a re-challenge with a chemotherapy that was previously discontinued prior to RGR treatment (11). Therefore, in the present study, the results of treatment after RGR failure in CRC were analyzed in our hospital, with the aim of identifying a suitable salvage treatment.

\section{Patients and methods}

Study design. This was a single-institutional retrospective study performed at Ina Central Hospital (Ina, Japan). All patients were treated by the authors named in this report. The patients' medical records were reviewed after all of the patients had died. This retrospective study was approved by the institutional review board, and the requirement to obtain patient consent was waived.

Treatment. A total of 17 patients with metastatic CRC who had been treated with RGR at the Department of Surgery and 
Medical Oncology of Ina Central Hospital between May 2013 and August 2015, following standard treatment with fluoropyrimidine and oxaliplatin or irinotecan, with bevacizumab, and cetuximab or panitumumab (for patients with wild-type KRAS only) were included in the analysis. Subsequent to RGR failure, patients were treated with another anticancer drug or received best supportive care (BSC) after a comprehensive assessment by the attending doctors and with patients' informed consent. In total, 12 patients $(70.6 \%)$ were treated with an anticancer drug, and the remaining 5 patients (29.4\%) received BSC.

Statistical analysis. The mean overall survival times from the start of RGR treatment (OS-1) and from the discontinuation of RGR treatment (OS-2) were measured. The data were compared with respect to the consecutive treatment following RGR failure by the Kaplan-Meier method with a log-rank test. The duration of BSC was compared using a Student's t-test. Statistical analysis was performed by JMP ${ }^{\circledR} 13$ software (SAS Institute Inc., Cary, NC, USA). All P-values were two-sided and $\mathrm{P}<0.05$ was considered to indicate a statistically significant difference.

\section{Results}

Patient characteristics. The clinicopathological characteristics of the patients are summarized in Table I. In total, 9 male and 8 female patients were included in the study, and the mean age was 64.2 years. Exon 2 of the KRAS gene was wild-type in 8 patients and mutated in 9 . The primary tumors were located on the right side in 8 patients (including 2 in the transverse colon) and on the left in 10. The median duration of RGR treatment was 14.5 weeks. RGR dosages were adjusted during the treatment in all patients, and the mean relative dose intensity was $56.5 \%$. Imaging revealed that RGR treatment did not lead to any complete or partial responses, as assessed using the Response Evaluation Criteria In Solid Tumors version 1.1 (12).

According to Common Terminology Criteria for Adverse Events (CTCAE) version 4.0 (13), no hematological toxicities of grade 3 or 4 were observed during RGR treatment. Non-hematological toxicities of grade 3 or 4 were observed in 9 patients (52.9\%), including hand-foot syndrome (4 patients), hypertension (1 patient), myalgia (1 patient), liver dysfunction (1 patient), diarrhea (1 patient) and mucositis (1 patient). RGR was discontinued due to disease progression in 14 patients and non-hematological toxicities in 3 .

At the point of RGR treatment discontinuation, 1 patient had an Eastern Cooperative Oncology Group performance status (PS) of 0, 14 had a PS of 1, and two had a PS of 2 (14). Metastatic tumors at three sites were detected in 2 patients, at two sites in 9 patients, and at one site in 6 patients (Table I).

The mean age, RGR treatment duration, and relative dose intensity did not differ significantly between the patients who underwent further anticancer treatment and those who received BSC following RGR (Table II).

Treatment and responses following RGR failure. Subsequent to RGR failure, 5 patients were treated with capecitabine, 3 received TAS-102, 2 received 5-fluorouracil (5-FU)/leucovorin (LV), 1 received S1 with irinotecan, and 1 received FOLFOX (oxaliplatin with 5-FU and folinic acid). In addition, 7 of these patients also received bevacizumab, while cetuximab was
Table I. Summary of the clinicopathological characteristics of the patients $(n=17)$.

\begin{tabular}{lr}
\hline Variable & Value \\
\hline Age, years & \\
Mean & 64.2 \\
Range & $42-86$ \\
Sex, $\mathrm{n}$ & \\
Male & 9 \\
Female & 8 \\
Primary tumor location, $\mathrm{n}$ & \\
Cecum & 1 \\
Ascending colon & 4 \\
Transverse colon & 2 \\
Descending colon & 2 \\
Sigmoid colon & 4 \\
Rectum & 4 \\
KRAS status of primary site, $\mathrm{n}$ & \\
Wild-type & 8 \\
Mutated & 9 \\
Performance status at discontinuation & \\
of RGR treatment, $\mathrm{n}$ & \\
0 & 14 \\
1 &
\end{tabular}

Number of metastatic sites at

discontinuation of RGR treatment, $n$

$1 \quad 6$

209

322

RGR treatment duration, weeks

Mean $\quad 14.6$

Range 2-38

Relative dose intensity of RGR, \%

Mean

Range

$26.3-81.1$

Reason for discontinuation of RGR, $n$

Progressive disease

14

Non-hematological adverse event

RGR, regorafenib.

administered in 1 patient along with 5-FU/LV (Table III). In 7 patients $(41.2 \%)$, a second additional treatment after RGR failure was administered, including TAS-102 in 2 patients, S1 in 2 patients, and capecitabine with irinotecan, capecitabine, and UFT each in 1 patient. The duration of treatment was 6.1 weeks on average. Additionally, 4 patients (23.5\%) received a third treatment, of which only 1 patient was treated with S1 plus oxaliplatin for 14 weeks, and the others discontinued treatment within two weeks (Table IV). In all patients who received chemotherapy following RGR failure, anticancer treatment was discontinued because of disease progression, and not PS deterioration. Imaging 
Table II. Clinical characteristics of patient groups divided by the treatment following RGR discontinuation.

\begin{tabular}{|c|c|c|c|c|}
\hline Variable & All patients & $\begin{array}{l}\text { Anticancer treatment } \\
\text { after RGR }(n=12)\end{array}$ & $\begin{array}{c}\text { BSC after } \\
\text { RGR }(n=5)\end{array}$ & $\begin{array}{c}\text { P-value } \\
\text { (Student's t-test) }\end{array}$ \\
\hline Age, years ${ }^{a}$ & 64.5 & 61.4 & 70.4 & 0.127 \\
\hline Duration of RGR, weeks ${ }^{\mathrm{a}}$ & 12.4 & 10.1 & 18.0 & 0.07 \\
\hline Relative dose intensity of RGR, $\%^{\mathrm{a}}$ & 51.4 & 51.5 & 51.0 & 0.968 \\
\hline \multicolumn{5}{|l|}{ Number of metastatic sites ${ }^{b}$} \\
\hline 1 & & 5 & 2 & \\
\hline 2 & & 7 & 3 & \\
\hline \multicolumn{5}{|l|}{ Reason for RGR discontinuation ${ }^{\mathrm{b}}$} \\
\hline Progressive disease & & 9 & 5 & \\
\hline Non-hematological AE & & 3 & 0 & \\
\hline
\end{tabular}

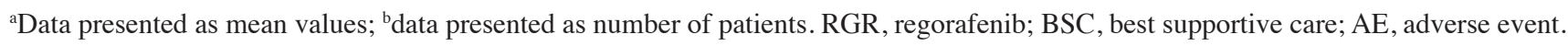

Table III. Anticancer treatments administered following RGR failure.

\begin{tabular}{|c|c|}
\hline Treatment & No. of patients \\
\hline Capecitabine ( \pm bevacizumab) & 5 \\
\hline TAS-102 & 3 \\
\hline 5-FU/levofolinate ( \pm cetuximab) & 2 \\
\hline $\mathrm{S} 1$ + irinotecan & 1 \\
\hline FOLFOX & 1 \\
\hline
\end{tabular}

5-FU, 5-fluorouracil; FOLFOX, oxaliplatin, 5-FU and folinic acid.

Table IV. Number of lines of chemotherapy administered following RGR failure.

\begin{tabular}{lc} 
No. of lines & No. of patients $(\%)$ \\
\hline 1 & $12(70.6)$ \\
2 & $7(41.2)$ \\
3 & $4(23.5)$ \\
\hline
\end{tabular}

revealed that treatment following RGR failure did not lead to any complete or partial responses. All patients succumbed to the primary disease, and all data were analyzed after their deaths.

Adverse events. According to the CTCAE version 4.0, no hematological or non-hematological toxicities of grade 3 or 4 were observed during the anticancer treatment following RGR failure.

Survival. Among all 17 patients, the mean OS-1 was 35.8 weeks and the mean OS-2 was 23.3 weeks. The patients who received only BSC after discontinuing RGR had a mean OS-1 of 27.0 weeks and OS-2 of 9.0 weeks. The patients who received anticancer treatment (comprising a mean of 18.7 weeks of consecutive anticancer chemotherapy and 10.6 weeks of BSC) after RGR failure had a mean OS-1 of 39.5 weeks and
OS-2 of 29.3 weeks (Table V; Figs. 1 and 2). The difference in OS-2 between the patients who received further anticancer treatment and those who did not was statistically significant $(\mathrm{P}=0.0003$; log-rank test); however the difference in OS-1 was not significant ( $\mathrm{P}=0.1958$; log-rank test). The duration of BSC received did not differ significantly between patients who received further anticancer treatment and those who did not ( $\mathrm{P}=0.639$; Student's t-test).

\section{Discussion}

Other than the use of RGR or TAS-102, there is no set strategy for the treatment of patients with metastatic CRC after the failure of standard treatment comprising fluoropyrimidines, irinotecan, oxaliplatin, bevacizumab and anti-epidermal growth factor receptor antibodies, $(11,15,16)$.

As Masuishi et al (17) reported, improved salvage therapies are required for CRC. In their study, RGR and TAS-102 were effective and safe to use as salvage therapies; however, the most beneficial order in which to use these drugs remains to be clarified, and the heterogeneity of the population of patients receiving these therapies hampers attempts to answer this question (16). It has been reported that RGR may have a resensitizing effect on tumors that have previously failed to respond to anticancer treatments (10). Clinical trials to investigate the value of reusing a previously failed drug after RGR treatment are underway $(8,18)$.

The current retrospective study showed that $70.5 \%$ of patients were fit for further anticancer treatment after RGR treatment, and these patients survived longer than those who did not receive further chemotherapy after RGR failure. Furthermore, the duration of BSC did not differ significantly between the patients who received anticancer therapy and those who did not. It is possible that the difference in survival time was due to the conditions of the individual patient: All patients in the BSC group were unfit for consecutive anticancer drug treatment following RGR discontinuation. Therefore, although the effectiveness of further anticancer treatment is unclear, further treatment confers a possible survival benefit for patients who are sufficiently fit at the point of RGR failure. 
Table V. Survival times following RGR commencement and failure.

Mean duration (range), weeks

\begin{tabular}{|c|c|c|c|c|}
\hline \multirow[b]{2}{*}{ Period } & & & & \multirow[b]{2}{*}{ P-value } \\
\hline & All patients & $\begin{array}{l}\text { Anticancer treatment } \\
\text { after RGR group }\end{array}$ & $\begin{array}{l}\text { BSC after } \\
\text { RGR group }\end{array}$ & \\
\hline OS-1 & $35.9(8-60)$ & $39.5(26-60)$ & $27.0(8-50)$ & $0.1958^{\mathrm{a}}$ \\
\hline OS-2 & $23.4(6-52)$ & $29.3(11-52)$ & $9.4(5-16)$ & $0.0003^{\mathrm{a}}$ \\
\hline Duration of BSC & $10.6(5-27)$ & $10.6(5-27)$ & $9.4(5-18)$ & $0.6395^{\mathrm{b}}$ \\
\hline Duration of RGR treatment & $12.4(2-34)$ & $10.0(3-18)$ & $18.0(2-34)$ & $0.0721^{\mathrm{b}}$ \\
\hline
\end{tabular}


RGR discontinuation; BSC, best supportive care.

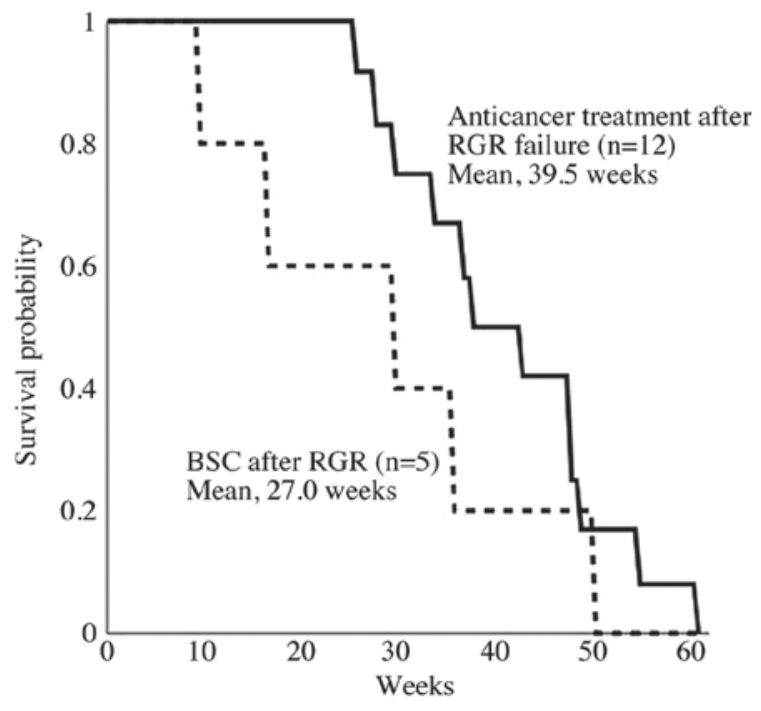

Figure 1. OS probability after start of RGR treatment (OS-1). OS-1 time was not significantly affected by consecutive anticancer treatment following RGR failure. OS, overall survival; RGR, regorafenib; BSC, best supportive care.

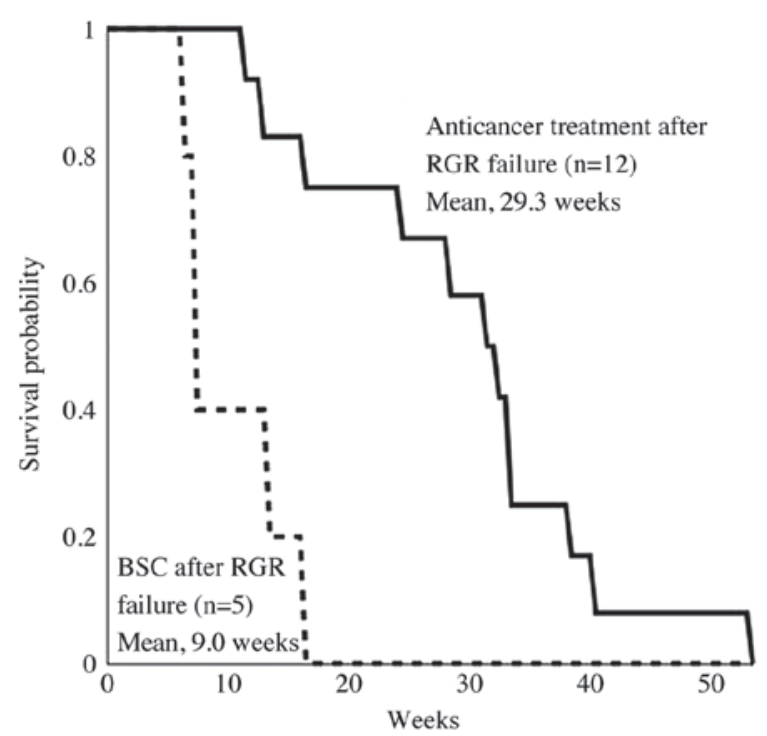

Figure 2. OS probability after discontinuance of RGR treatment (OS-2). OS-2 time was significantly longer in the group that received consecutive anticancer drug treatment after RGR failure. OS, overall survival; RGR, regorafenib; BSC, best supportive care.
RGR is not the final salvage treatment for CRC. Careful treatment to avoid adverse events is crucial, and accurate judgment may be required for discontinuing the anticancer treatment to maintain the quality of life of the patients.

In our institution, bevacizumab with fluoropyrimidines was the most frequently selected treatment regimen following RGR failure; however, the benefits of this approach over other regimens have not been evaluated. Biomarkers to enable clinicians to choose the optimal salvage therapy for CRC are necessary.

In conclusion, it will be beneficial for future research to establish an effective strategy for 'salvage' treatment for CRC, and to determine the optimal time during RGR treatment at which to switch to further anticancer therapy, as well as the order of treatment, without compromising the patients' quality of life towards the ends of their lives.

\section{References}

1. Ferlay I, Shin HR, Bray F, Forman D, Mathers C and Parkin DM: Estimates of worldwide burden of cancer in 2008: GLOBOCAN 2008. Int J Cancer 127: 2893-2917, 2010.

2. Siegel R, Ma J, Zou Z and Jemal A: Cancer statistics, 2014. CA Cancer J Clin 64: 9-29, 2014.

3. Tournigand C, André T, Achille E, Lledo G, Flesh M, Mery-Mignard D, Quinaux E, Cocteau C, Buyse M, Ganem G, et al: FOLFIRI followed by FOLFOX6 or the reverse sequence in advanced colorectal cancer: A randomized GERCOR study. J Clin Oncol 22: 229-237, 2004.

4. Clouch G, Gebbia V, Paoletti G, Giuliani F, Caruso M, Gebbia N, Carteni G, Agostara B, Pezzella G and Manzione L, et al: Phase III randomized trial of FOLFIRI versus FOLFOX4 in the treatment of advanced colorectal cancer: A multicenter study of the Gruppo Oncologico Dell'Italia Meridonale. J Clin Oncol 23: 4866-4875, 2005.

5. Grothey A, Sargent D, Goldberg RM and Schmoll HJ: Survival of patients with advanced colorectal cancer improves with the availability of fluorouracil-leucovorin, irinotecan, and oxaliplatin in the course of treatment. J Clin Oncol 22: 1209-1214, 2004.

6. Heinemann V, von Weikersthal LF, Decker T, Kiani A, Vehling-Kaiser U, Al-Batran SE, Heintges T, Lerchenmüller C, Kahl C, Seipelt G, et al: FOLFIRI plus cetuximab versus FOLFIRI plus bevacizumab as first-line treatment for patients with metastatic colorectal cancer (FIRE-3): A randomised, open-label, phase 3 trial. Lancet Oncol 15: 1065-1075, 2014.

7. Venook AP, Niedzwiecki D, Lenz HJ, Innocenti F, Mahoney MR, O'Neil BH, Shaw JE, Polite BN, Hochster HS, Atkins JN, et al: CALGB/SWOG 80405: Phase III trial of irinotecan/5-FU/leucovorin (FOLFIRI) or oxaliplatin/5-FU/leucovorin (mFOLFOX6) with bevacizumab (BV) or cetuximab (CET) for patients with KRAS wild-type (wt) untreated metastatic adenocarcinoma of the colon or rectum (MCRC). J Clin Oncol 32 (15 Suppl): 5s, 2014 (Suppl; abstr LBA3). 
8. Grothey A, Van Cutsem E, Sobrero A, Siena S, Falcone A, Ychou M, Humblet Y, Bouché O, Mineur L, Barone C, et al: Regorafenib monotherapy for previously treated metastatic colorectal cancer (CORRECT): An international, multicentre, randomised, placebo-controlled, phase 3 trial. Lancet 381: 303-312, 2013.

9. Li J, Qin S, Xu R, Yau TC, Ma B, Pan H, Xu J, Bai Y, Chi Y, Wang L, et al: Regorafenib plus best supportive care versus placebo plus best supportive care in Asian patients with previously treated metastatic colorectal cancer (CONCUR): A randomised, double-blind, placebo-controlled, phase 3 trial. Lancet Oncol 16: 619-629, 2015.

10. Wilcox R, Kidd M, Alberts S, Rubin J, Hartgers M, Mitchell J, Hubbard J, Pham A, Quevedo J, Yoon H, et al: P-0229: Efficacy of chemotherapy after treatment with regorafenib in metastatic colorectal cancer (MCRC). Ann Oncol 25 (Suppl 2): ii85, 2014

11. Grothey A: Regorafenib in metastatic colorectal cancer: Optima dosing and patient selection recommendations. Clin Adv Hematol Oncol 13: 514-517, 2015.

12. Eisenhauer EA, Therasse P, Bogaerts J, Schwartz LH, Sargent D, Ford R, Dancey J, Arbuck S, Gwyther S, Mooney M, et al: New response evaluation criteria in solid tumours: Revised RECIST guideline (version 1.1). Eur J Cancer 45: 228-247, 2009.

13. CTEP, NCI Investigation Drug Branch. CTEP Guidance: CTCAE v4.0 Grading Scales with Numeric Component, May 17, 2010. http://ctep.cancer.gov/protocolDevelopment/electronic applications/ctc.htm\#ctc_40. Accessed June 3, 2017.
14. Common Toxicity Criteria, version 2.0, April 30, 1999. http://ctep.cancer.gov/protocolDevelopment/electronic_applications/ docs/ctcv20 4-30-992.pdf.

15. Sueda T, Sakai D, Kudo T, Sugiura T, Takahashi H, Haraguchi N, Nishimura J, Hata T, Hayashi T, Mizushima T, et al: Efficacy and safety of Regorafenib or TAS-102 in patients with metastatic colorectal cancer refractory to standard therapies. Anticancer Res 36: 4299-4306, 2016.

16. Arita S, Shirakawa T, Matsushita Y, Shimokawa HK, Hirano G, Makiyama A, Shibata Y, Tamura S, Esaki T, Mitsugi K, et al: Efficacy and safety of TAS-102 in clinical practice of salvage chemotherapy for metastatic colorectal cancer. Anticancer Res 36: 1959-1966, 2016.

17. Masuishi T, Taniguchi H, Hamauchi S, Komori A, Kito Y, Narita Y, Tsushima T, Ishihara M, Todaka A, Tanaka T, et al: Regorafenib versus Trifluridine/Tipiracil for refractory metastatic colorectal cancer: A retrospective comparison. Clin Colorectal Cancer 16: e15-e22, 2017.

18. Kidd MT, Wilcox RE, Rogers J, Eng C, Saadat S, Lenz HJ, Hubbard JM and Grothey A: Efficacy of chemotherapy after treatment with regorafenib in metastatic colorectal cancer (mCRC). J Clin Oncol 33 (3 Suppl): S678, 2015. 